AperTO - Archivio Istituzionale Open Access dell'Università di Torino

\title{
Phototransformation of 4-phenoxyphenol sensitised by 4-carboxybenzophenone: Evidence of new photochemical pathways in the bulk aqueous phase and on the surface
}

\section{This is the author's manuscript}

Original Citation:

\section{Availability:}

This version is available http://hdl.handle.net/2318/141264

since 2016-10-10T13:08:27Z

Published version:

DOI:10.1016/j.atmosenv.2013.09.036

Terms of use:

Open Access

Anyone can freely access the full text of works made available as "Open Access". Works made available under a Creative Commons license can be used according to the terms and conditions of said license. Use of all other works requires consent of the right holder (author or publisher) if not exempted from copyright protection by the applicable law. 


\section{(6) \\ UNIVERSITÀ DEGLI STUDI DI TORINO}

This Accepted Author Manuscript (AAM) is copyrighted and published by Elsevier. It is posted here by agreement between Elsevier and the University of Turin. Changes resulting from the publishing process - such as editing, corrections, structural formatting, and other quality control mechanisms - may not be reflected in this version of the text. The definitive version of the text was subsequently published in

E. De Laurentiis, J. Socorro, D. Vione, E.Quivet, M. Brigante, G. Mailhot, H.Wortham, S. Gligorovski. Phototransformation of 4-phenoxyphenol sensitised by 4-carboxybenzophenone in aqueous solution and at the aerosol interface: Evidence of new photochemical pathways in the bulk aqueous phase and on the surface of aerosol deliquescent particles. Atmos. Environ. 2013, $81,569-578$.

DOI: $10.1016 /$ j.atmosenv.2013.09.036.

You may download, copy and otherwise use the AAM for non-commercial purposes provided that your license is limited by the following restrictions:

(1) You may use this AAM for non-commercial purposes only under the terms of the CC-BY-NCND license.

(2) The integrity of the work and identification of the author, copyright owner, and publisher must be preserved in any copy.

(3) You must attribute this AAM in the following format:

E. De Laurentiis, J. Socorro, D. Vione, E.Quivet, M. Brigante, G. Mailhot, H.Wortham, S. Gligorovski. Phototransformation of 4-phenoxyphenol sensitised by 4-carboxybenzophenone in aqueous solution and at the aerosol interface: Evidence of new photochemical pathways in the bulk aqueous phase and on the surface of aerosol deliquescent particles. Atmos. Environ. 2013, $81,569-578$.

DOI: 10.1016/j.atmosenv.2013.09.036 (http://www.elsevier.com/locate/atmosenv). 
Phototransformation of 4-phenoxyphenol sensitised by 4-carboxybenzophenone in aqueous solution and at the aerosol interface: Evidence of new photochemical pathways in the bulk aqueous phase and on the surface of aerosol deliquescent particles

Elisa De Laurentiis ${ }^{2}$, Joanna Socorro ${ }^{1}$, Davide Vione ${ }^{2,3 *}$, Etienne Quivet $^{1}$, Marcello Brigante, ${ }^{4}$ Gilles Mailhot, ${ }^{4}$ Henri Wortham ${ }^{1}$, Sasho Gligorovski ${ }^{1}{ }^{*}$

${ }^{1}$ Aix-Marseille University, CNRS, FRE 3416, 3 Place Victor Hugo, 13331 Marseille Cedex 03, France

${ }^{2}$ Dipartimento di Chimica, Università di Torino, Via P. Giuria 5, 10125 Torino, Italy

${ }^{3}$ Centro Interdipartimentale NatRisk, Università di Torino, Via L. Da Vinci 44, 10095 Grugliasco (TO), Italy.

${ }^{4}$ Clermont Université, Université Blaise Pascal, Institut de Chimie de Clermont-Ferrand UMR 6296, BP 10448, F-63000 Clermont-Ferrand, France.

Submitted to Atmospheric Environment on 14/February/2013

Correspondence to either author:

*Davide Vione E-mail: davide.vione@unito.it

*Sasho GligorovskiＥ-mail: saso.gligorovski@univ-amu.fr 


\begin{abstract}
In addition to direct photolysis, degradation of organic compounds by solar light can also occur by indirect photolysis or photo-sensitised processes. These reactions are important because they are involved in, among others, direct and indirect climate changes, adverse health effects from inhaled particles, effects on cloud chemistry and ozone production. In this work, the importance of atmospheric photo-sensitisation is evaluated in bulk aqueous solution and on the surface of aerosol deliquescent particles. Irradiation experiments in aqueous solution indicate that 4-carboxybenzophenone (CBP) is able to photosensitise the degradation of 4-phenoxyphenol (4PP). The process takes place via the CBP triplet state $\left({ }^{3} \mathrm{CBP} *\right)$, which has an oxidising nature. 4PP is fluorescent, unlike the photosensitizer $\mathrm{CBP}$, with two emission bands at $\sim 320$ and $\sim 380 \mathrm{~nm}$. However, addition of CBP to a 4PP solution considerably decreases the intensity of 4PP fluorescence bands and causes a very intense new band to appear at $\sim 420 \mathrm{~nm}$. This behaviour suggests a possible interaction between CBP and 4PP in solution, which could favour further light-induced processes. Moreover, the new band overlaps with the fluorescence spectrum of atmospheric HULIS (HUmic-LIke Substances), suggesting that supramolecular photosensitizer-substrate interactions may have a role in HULIS fluorescence properties. The interaction between CBP and 4PP coated on silica particles (gas-solid system) was also investigated under simulated sunlight, and in the presence of variable relative humidity. The water molecules inhibit the degradation of 4PP, induced by ${ }^{3} \mathrm{CBP}^{*}$ on the surface of aerosol particles, indicating that the process could be even faster on particles than in solution. We demonstrate that phenol substances adsorbed on aerosol surfaces and in bulk solution are substantially altered upon photosensitised processes.
\end{abstract}

Keywords: atmospheric photosensitisers; triplet-sensitised photochemical reactions; humiclike substances; atmospheric aqueous phase; atmospheric aerosol; gas-solid reactivity. 


\section{Introduction}

Phenols and substituted phenols are important sources of secondary organic aerosol in the atmosphere (Yee et al., 2013). They are emitted by automobile exhaust, wood burning and industrial sources (Lesh and Mead, 1985; Hawthorne et al., 1988; Hawthorne et al., 1989), but wood burning is expected to be a major source of atmospheric phenols in winter (Hawthorne et al., 1992).

Phenols and substituted phenols are produced by lignin pyrolysis and they are thought to be specific tracers for woodsmoke (Simoneit, 2002; Hawthorne et al., 1989; Hawthorne et al., 1988; Bari et al., 2009; Perzon, 2010, Dron et al., 2010). Lignin is the richest source of aromatics in the atmosphere. Aromatic compounds such as conyferyl alcohol, coumaryl alcohol and sinapyl alcohol in lignin are mainly linked by $\mathrm{C}-\mathrm{O}$ and $\mathrm{C}-\mathrm{C}$ bonds. Dimeric chemicals containing $\mathrm{C}-\mathrm{O}$ bonds such as $\beta-\mathrm{O}-4, \alpha-\mathrm{O}-5$ and 4-O-5 have been used as lignin model compounds, because $\mathrm{C}-\mathrm{O}$ is an abundant linkage type in lignin. Among various lignin model compounds, 4-phenoxyphenol (4PP) has been widely used to represent the 4-O-5 bond (Park et al., 2013).

On the other hand, atmospheric aerosols from biomass burning include significant amounts of aromatic carbonyls that can potentially act as photosensitisers, such as 4carboxybenzophenone (CBP) (Vione et al., 2006; Gomez Alvarez et al., 2012). These compounds may also be formed as photolysis products of polycyclic aromatic hydrocarbons (PAHs) (Simoneit et al., 1993; Jang and McDow, 1995; Jang and McDow, 1997; Anastasio et al., 1997; Vione et al., 2006). In solution, the excited triplet states of aromatic carbonyls such as CBP can be quenched efficiently by phenols and substituted phenols (Canonica et al., 2000). Therefore, it is assumed that the same process might occur on the surface or in the bulk of atmospheric aerosols.

In this study the degradation of 4PP sensitised by CBP was assessed in the aqueous phase (proxy of atmospheric hydrometeors) and on the surface of silica particles (proxies of airborne particles) with variable relative humidity (RH), i.e. up to $95 \%$. The determination by laser flash photolysis of the reaction rate constant between $4 \mathrm{PP}$ and ${ }^{3} \mathrm{CBP} *$ allowed the development of a kinetic model to account for the results of steady irradiation experiments. Monitoring of fluorescence upon irradiation of CBP and 4PP in solution was carried out, to check for the possible formation of compounds with fluorescence properties similar to HULIS. 


\section{Experimental set-up}

All reagents used in the experiments were of analytical grade and were used as received. Eluents for liquid chromatography were of gradient grade. Water used was of Milli-Q quality.

\section{Laser flash photolysis experiments}

For $355 \mathrm{~nm}$ excitation, experiments were carried out using the third harmonic $\left(\lambda_{\mathrm{exc}}=355 \mathrm{~nm}\right)$ of a Quanta Ray GCR 130-01 Nd:YAG laser system instrument, used in a right-angle geometry with respect to the monitoring light beam. The single pulses were $c a .9 \mathrm{~ns}$ in duration, with an energy of $\sim 45 \mathrm{~mJ} /$ pulse. Individual cuvette samples ( $3 \mathrm{~mL}$ volume) were used for a maximum of two consecutive laser shots to avoid degradation of solutes. The transient absorbance at the pre-selected wavelength was monitored by a detection system consisting of a pulsed xenon lamp $(150 \mathrm{~W})$, monochromator and a photomultiplier (1P28). A spectrometer control unit was used for synchronising the pulsed light source and programmable shutters with the laser output. The signal from the photomultiplier was digitised by a programmable digital oscilloscope (HP54522A). A 32 bits RISC-processor kinetic spectrometer workstation was used to analyse the digitised signal.

Stock solutions of CBP and 4PP were prepared in Milli-Q water and were mixed in an appropriate volume just before each experiment, to obtain the desired concentration of all the species. To derive the second-order rate constant for the quenching of ${ }^{3} \mathrm{CBP}^{*}$, plots were made of the first-order decay constant of ${ }^{3} \mathrm{CBP}^{*}$ (determined from the regression lines of the logarithmic decays of ${ }^{3} \mathrm{CBP}^{*}$ monitored at $550 \mathrm{~nm}$ ) against the concentration of 4PP. All experiments were performed at ambient temperature $(295 \pm 2 \mathrm{~K})$ and in aerated solution.

\section{Aqueous solution experiments}

\section{Irradiation procedure}

Solutions to be irradiated ( $5 \mathrm{~mL}$ volume) were placed in cylindrical Pyrex glass cells $(4.0 \mathrm{~cm}$ diameter, $2.5 \mathrm{~cm}$ height) closed with a lateral screw cap, and irradiated from the top under a $20 \mathrm{~W}$ Philips TL09N UVA lamp with emission maximum at $355 \mathrm{~nm}$. Samples were magnetically stirred during irradiation. Lamp UV irradiance on top of the solutions was $70.3 \pm 5.4 \mathrm{~W} \mathrm{~m}^{-2}$ (290-400 nm), measured with a CO.FO.ME.GRA. power metre equipped with a UV-sensitive probe. The incident photon flux in the solution volume was $(5.32 \pm 0.41) \cdot 10^{-5}$ Einstein $\mathrm{L}^{-1} \mathrm{~s}^{-1}$, actinometrically determined with the ferrioxalate method (Kuhn et al., 2004). The lamp emission spectrum was measured with a calibrated Ocean Optics USB2000 CCD spectrophotometer and normalised to the actinometry data, to obtain the spectral photon flux density reported in Figure 1. The Figure also reports the absorption spectra (molar absorption coefficients) of CBP and 4PP, measured with a Varian Cary 100 
Scan UV-Vis double-beam spectrophotometer, using quartz cuvettes (Hellma, $1.00 \mathrm{~cm}$ optical path length). The same instrument was used to measure the absorption spectra of irradiated solutions.

\section{Analysis by liquid chromatography and kinetic data treatment}

Irradiated samples were withdrawn after the scheduled irradiation time and analysed by highperformance liquid chromatography coupled with diode-array detection (HPLC-DAD). The used VWR-Hitachi LaChrome Elite instrument was equipped with L-2200 Autosampler (injection volume $60 \mu \mathrm{L}$ ), L-2130 quaternary pump for low-pressure gradients, L-2300 column oven (set at $40^{\circ} \mathrm{C}$ ), and L-2455 DAD detector. The column used was a RP-C18 LichroCART (VWR Int., length $125 \mathrm{~mm}$, diameter $4 \mathrm{~mm}$ ), packed with LiChrospher $100 \mathrm{RP}$ 18 (5 $\mu \mathrm{m}$ diameter). Elution was carried out with a 55: 45 mixture of methanol: $5 \mathrm{mM}$ tetrabutylammonium bromide $+\mathrm{H}_{3} \mathrm{PO}_{4}$ in water $(\mathrm{pH} 2.8)$ at $1.0 \mathrm{~mL} \mathrm{~min}{ }^{-1}$ flow rate, with detection at $225 \mathrm{~nm}(4 \mathrm{PP})$ and $262 \mathrm{~nm}(\mathrm{CBP})$. Under these conditions the retention times were $5.8 \mathrm{~min}(\mathrm{CBP})$ and $6.7 \mathrm{~min}(4 \mathrm{PP})$, the column dead time being $0.9 \mathrm{~min}$.

The time evolution data of CBP and 4PP were fitted with pseudo-first order equations of the form $\left(C_{\mathrm{t}} C_{\mathrm{o}}^{-1}\right)=e^{-k \cdot t}$, where $C_{\mathrm{t}}$ is the concentration of the substrate (CBP or 4PP) at time $t, C_{\mathrm{o}}$ its initial concentration, and $k$ (fit variable) the pseudo-first order degradation rate constant. The initial transformation rate is $R=k C_{\mathrm{o}}$. Errors on $k$ were derived from the scattering of experimental data around each fit curve. The reported errors on $R(\mu \pm \sigma)$ largely depended on $k$ errors, because errors on $C_{\mathrm{o}}$ (derived from calibration curves) were much lower. The reproducibility of repeated runs was around 10-15\%. In some cases, experimental rate data were fitted with rather complex equations derived from kinetic models. The error associated to the floating variables depended both on data scattering around the fit function and on uncertainty of constant parameters, which was taken into account with error propagation rules.

\section{Fluorescence measurements}

Fluorescence of solutions before and after irradiation was measured with an Agilent Cary Eclipse fluorescence spectrophotometer. The slit widths were set at $10 \mathrm{~nm}$ for both excitation and emission. To obtain fluorescence EEM (Excitation-Emission Matrix) spectra, excitation wavelengths $\left(\lambda_{\text {ex }}\right)$ were varied from 210 to $500 \mathrm{~nm}$ at $10 \mathrm{~nm}$ steps. For each excitation wavelength, the emission $\left(\lambda_{\text {em }}\right)$ was detected from 220 to $600 \mathrm{~nm}$ at $10 \mathrm{~nm}$ steps, using a scanning speed of $600 \mathrm{~nm} \min ^{-1}$ and a photomultiplier voltage of $600 \mathrm{~V}$. The Raman peak of ultra-pure water, obtained with an excitation wavelength of $350 \mathrm{~nm}$, was used as a test for signal stability during measurements. 


\section{Irradiation of coated silica particles}

\section{Sampling and experimental procedure}

The highly polar surfaces of commercial silica particles such as Aerosil R812 may simulate, as a first approximation, inorganic oxide aerosols found in the environment (Barbas et al., 1996). A stock solution of $4 \mathrm{PP}$ and CBP at $1: 1$ mass ratio with a total concentration of $\approx 1$ (mg $\mathrm{mL}^{-1}$ ) in dichloromethane was prepared in advance. A $10 \mathrm{~mL}$ aliquot of this solution was mixed with $1 \mathrm{~g}$ of Silica particles Aerosil R812, in a Pyrex bulb with a volume of $500 \mathrm{~cm}^{3}$. The bulb was wrapped with aluminium foil and attached to a rotary evaporator, where the particles were dried for about $40 \mathrm{~min}$ at $40^{\circ} \mathrm{C}$ and $850 \pm 85 \mathrm{mbar}$, obtaining surface concentrations of $4 \mathrm{PP}$ and $\mathrm{CBP}$ of $\left.\approx 2(\mathrm{ng} \mathrm{cm})^{-2}\right)$ for the experiments. The initial coating of both 4PP and CBP was $1 \%(w / w)$, expressed as the mass fraction of organics compared to the Aerosil R812 carrier.

The dried coated silica particles $(420 \mathrm{mg}$ ) were then exposed to simulated sunlight emitted by a broadband continuous light source ( $300 \mathrm{~W}$ xenon lamp), placed at a distance of $10 \mathrm{~cm}$ from the bulb. The rotation of the bulb ensured a homogeneous irradiation of the particles during the whole experiment. A dried or humidified (the latter by means of a bubbler) air flow of 100 $\mathrm{mL} \min ^{-1}$ was kept constant for all the experiments. The relative humidity (RH) was measured throughout the experiments with a humidity probe (Hydrolog NT, Rotronic, USA). RH was kept constant at $0 \%, 70 \pm 2 \%$ and $95 \pm 2 \%$. The temperature of the bulb was maintained at $25 \pm 1{ }^{\circ} \mathrm{C}$.

The solid silica particles coated with $4 \mathrm{PP} / \mathrm{CBP}$ were irradiated with simulated sunlight for 10 hours. A $60 \mathrm{mg}$ aliquot of the particles was taken every two hours and mixed with $20 \mathrm{~mL}$ dichloromethane and few mg of sodium sulphate, the latter to remove water traces. Each experiment was repeated twice.

Following the light exposure of the particles, they were solvent-extracted in dichloromethane by $30 \mathrm{~min}$ sonication (Branson 3510, USA). Extraction was followed by $15 \mathrm{~min}$ of centrifugation (6000 rpm) (Sorvall Legend Micro 17, TermoFisher Scientific, France) to separate the organic compounds dissolved in dichloromethane from the silica particles. The separated extracts were then filtered with iso-disc filters (PTFE $0.45 \mu \mathrm{m}$ ) (Sigma-Aldrich, France). A $0.5 \mathrm{~mL}$ aliquot of the filtered sample was mixed with $20 \mu \mathrm{L}$ internal standard

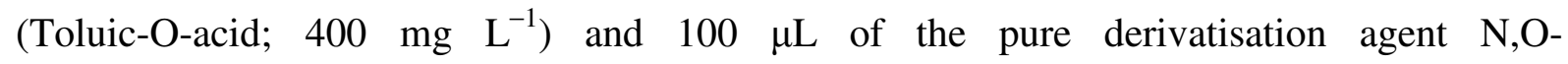
bis(trimethylsilyl)trifluoroacetamide (BSTFA). BSTFA was used by some of us in previous studies and the derivatisation procedure is explained in detail in Net et al. (2009). The prepared mixture was placed in stove at $70^{\circ} \mathrm{C}$ for about $30 \mathrm{~min}$, and then for another $30 \mathrm{~min}$ at ambient temperature. Finally, the clear solutions were analysed by gas chromatography mass spectrometry (GC-MS). 


\section{GC-MS analysis}

The extract solutions were analysed by GC-MS using electron impact ionisation mode (70 $\mathrm{eV}$ ), according to the following parameters: column THERMO TR-5MS (internal diameter $0.25 \mathrm{~mm}$, length $30 \mathrm{~m}$, film thickness $0.25 \mu \mathrm{m}$ ), carrier gas: He with $1 \mathrm{~mL} \mathrm{~min}^{-1}$ flow rate, injection volume: $1 \mu \mathrm{L}$, inlet temperature: $250^{\circ} \mathrm{C}$, interface temperature: $330^{\circ} \mathrm{C}$, with the following temperature program: hold $1 \mathrm{~min}$ at $80^{\circ} \mathrm{C}$; increase temperature to $220^{\circ} \mathrm{C}$ at a rate of $15^{\circ} \mathrm{C} \mathrm{min}{ }^{-1}$; increase temperature to $300^{\circ} \mathrm{C}$ at $25^{\circ} \mathrm{C} \mathrm{min}{ }^{-1}$; hold for $15 \mathrm{~min}$ at $300^{\circ} \mathrm{C}$. A Combi PAL autosampler was used for automated analysis.

\section{Results and Discussion}

\section{Laser flash photolysis experiments}

The 355-nm laser excitation of CBP in aqueous solution leads to the formation of a transient spectrum with two absorption maxima at 340 and at $540-550 \mathrm{~nm}$, which is attributed to the triplet state of $\mathrm{CBP}\left({ }^{3} \mathrm{CBP} *\right)$. The uniform decay of the transient signal excludes that other significantly absorbing species are formed upon laser excitation of CBP. In the presence of $4 \mathrm{PP}\left(5.5 \times 10^{-4} \mathrm{M}\right)$, the ${ }^{3} \mathrm{CBP}^{*}$ transient spectrum completely decays after $\sim 2 \mu \mathrm{s}$ and a new long-lived transient, with maximum absorption around $410 \mathrm{~nm}$ (see Figure 2) is observed. From literature data, the long-lived transient can be identified as the phenoxy radical of 4PP (Gadosy et al., 1999). The insert in Figure 2 shows the first-order decay constant of the CBP triplet state, $k_{{ }^{3} C B P^{*}}$, as a function of the concentration of 4PP. From the linear fit of experimental data reported in the figure, according to the Stern-Volmer approach, we can obtain the second-order rate constant between ${ }^{3} \mathrm{CBP} *$ and $4 \mathrm{PP}, k_{{ }^{3} B P^{*}, 4 P P}=(8.62 \pm 0.91) \cdot 10^{8}$ $\mathrm{M}^{-1} \mathrm{~s}^{-1}$. The ${ }^{3} \mathrm{CBP}^{*}$ decay constant in the absence of $4 \mathrm{PP}$, obtained as the line intercept, is $k_{{ }^{3} B P^{*}}=(6.54 \pm 0.46) \cdot 10^{5} \mathrm{~s}^{-1}$.

\section{Experiments under continuous irradiation}

$\mathrm{CBP}$ underwent phototransformation when irradiated alone under the UVA lamp. 4PP alone also underwent direct photolysis to some extent, but its photodegradation was considerably accelerated in the presence of CBP. This finding suggests that CBP can photosensitise the transformation of 4PP, in general agreement with laser flash photolysis data that highlight the reactivity between ${ }^{3} \mathrm{CBP} *$ and $4 \mathrm{PP}$. For instance, the rate of direct photolysis of $0.1 \mathrm{mM} 4 \mathrm{PP}$ was less than $10 \%$ of the degradation rate of $0.1 \mathrm{mM} 4 \mathrm{PP}$ in the presence of $70 \mu \mathrm{M}$ CBP. Figure 3 shows the trends with 4PP concentration of the transformation rate of 4PP $\left(R_{4 \mathrm{PP}}, 3 \mathrm{a}\right)$ and of the transformation rate of $\mathrm{CBP}\left(R_{\mathrm{CBP}}, 3 \mathrm{~b}\right)$. Both rates increase with 4PP concentration, although the increase of $R_{4 \mathrm{PP}}$ is much more marked. The correction of $R_{4 \mathrm{PP}}$ to subtract the direct photolysis was comparable to the experimental error on the initial rate. 
The results of laser flash photolysis experiments suggest that ${ }^{3} \mathrm{CBP} *$ could oxidise 4PP to the corresponding phenoxy radical, which is in general agreement with the known behaviour of phenolic compounds towards triplet sensitisers (Canonica et al., 2000; Canonica and Freiburghaus, 2001). Such a process would also involve reduction of CBP. Usually, the reduced radical species arising from such processes (formed by addition of an electron or a $\mathrm{H}$ atom) are recycled back to the starting compound (CBP in the present case) by reaction with molecular oxygen (Clark and Stonehill, 1972). In this scenario the presence of a substrate such as 4PP should inhibit the transformation of the sensitiser, by channelling tripletsensitizer reactions toward the regeneration of the starting compound (Maurino et al., 2008). However, this is not the case for the trend reported in Figure 3b. There is evidence that some reduced sensitisers could undergo further transformation processes in addition to the back reaction with $\mathrm{O}_{2}$ (De Laurentiis et al., 2013a). For instance, it has been shown that phenolic compounds enhance the photochemical transformation of nitro-polycyclic aromatic hydrocarbons that act as photosensitisers (Feilberg and Nielsen, 2000). The inhibition or enhancement of sensitiser degradation in the presence of the substrate would thus depend on the relative weight of back-recycling (by $\mathrm{O}_{2}$ ) of the reduced sensitiser vs. further transformation processes.

From laser flash photolysis results and in analogy with literature data concerning photosensitiser-substrate systems (Alegría et al., 1999; Bedini et al., 2012), the following reaction scheme can be proposed for $4 \mathrm{PP}$ and $\mathrm{CBP}$ under irradiation (ISC = inter-system crossing):

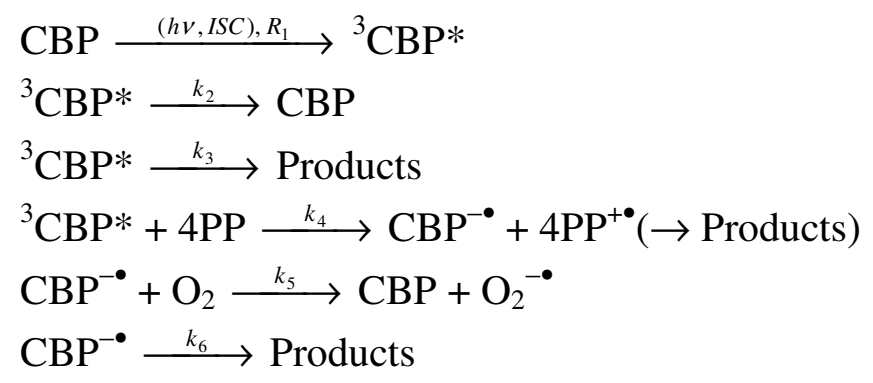

From laser flash photolysis data one has $k_{2}+k_{3}=(6.54 \pm 0.46) \cdot 10^{5} \mathrm{~s}^{-1}$ and $k_{4}=(8.62 \pm 0.91) \cdot 10^{8}$ $\mathrm{M}^{-1} \mathrm{~s}^{-1}$. Also note that the way reaction (4) is written is not intended to imply that the process would necessarily take place via electron transfer: it could be either $\mathrm{e}^{-}$or $\mathrm{H}$-atom transfer. In both cases the observed phenoxy radical would eventually be formed, as the radical cation produced by $\mathrm{e}^{-}$transfer would undergo rapid deprotonation to phenoxyl (Dixon and Murphy, 1976; Ma et al., 2000). In a previous paper (Net et al., 2009), we reported the energy difference HOMO-LUMO and the energy gap between the ground state and the first triplet state for both $4 \mathrm{PP}$ and $\mathrm{CBP}$, concluding that the mechanism between ${ }^{3} \mathrm{CBP} *$ and $4 \mathrm{PP}$ is a charge transfer rather than an energy transfer. In solution, the oxidation of phenolic 
substances by the excited triplet state of aromatic carbonyls occurs via electron transfer and/or hydrogen abstraction, depending on the solute-solvent interactions (Canonica et al., 2000). Net et al. (2009) have also shown that the phenoxy radicals arising from such processes are responsible for oligomer formation in aerosol particles via $\mathrm{C}-\mathrm{C}$ addition or $\mathrm{O}-\mathrm{C}$ addition mechanisms.

By applying the steady-state approximation to ${ }^{3} \mathrm{CBP}^{*}$ and $\mathrm{CBP}^{-\bullet}$, one obtains the following expressions for the initial transformation rates of $4 \mathrm{PP}$ and $\mathrm{CBP}$ :

$$
\begin{aligned}
R_{4 P P} & =\frac{R_{1} k_{4}[4 P P]}{k_{2}+k_{3}+k_{4}[4 P P]} \\
R_{C B P} & =R_{1} \frac{k_{3}\left(k_{5}\left[O_{2}\right]+k_{6}\right)+k_{4} k_{6}[4 P P]}{\left(k_{2}+k_{3}+k_{4}[4 P P]\right)\left(k_{5}\left[O_{2}\right]+k_{6}\right)}
\end{aligned}
$$

The experimental data shown in Figure 3 a were fitted with equation (7), $R_{1}$ being the only floating variable. The fit yielded $R_{1}=(3.3 \pm 0.5) \cdot 10^{8} \mathrm{M} \mathrm{s}^{-1}$ as the initial formation rate of ${ }^{3} \mathrm{CBP}^{*}$. Equation (8) with the known values of $R_{1}$ (previous fit), $k_{2}+k_{3}$ and $k_{4}$ (flash photolysis experiments), and with $\left[\mathrm{O}_{2}\right]=0.3 \mathrm{mM}$ (as per oxygen solubility in air-equilibrated solutions) was used to fit the $R_{\mathrm{CBP}}$ data of Figure $3 \mathrm{~b}$. The fit yielded $k_{3}=(1.0 \pm 0.3) \cdot 10^{4} \mathrm{~s}^{-1}$ and $k_{6}\left(k_{5}\left[\mathrm{O}_{2}\right]\right)^{-1}=0.10 \pm 0.04$. The fit quality and the values of $k_{3}$ and $k_{6}\left(k_{5}\left[\mathrm{O}_{2}\right]\right)^{-1}$ were independent of the actual value chosen for $k_{5}$, which could be varied over a wide range $\left(10^{4}\right.$ $10^{10}$ ) without affecting the fit results. This finding is somewhat expected when looking at the reaction scheme, where the important issue is the branching ratio of reactions (5) and (6) rather than the actual values of the rate constants. The only requirement for $k_{5}$ and $k_{6}$ is that they are sufficiently high to enable application of the steady-state approximation to $\mathrm{CBP}^{-\bullet}$.

The fit results suggest that ${ }^{3} \mathrm{CBP} *$ would evolve by thermal deactivation to ground-state $\mathrm{CBP}$ (reaction 2) rather than by other transformation processes (reaction 3), unless 4PP is present (reaction 4). Moreover, $\sim 10 \% \mathrm{CBP}^{-\bullet}$ could be further transformed (reaction 6) but the remainder would be recycled back to CBP by oxygen (reaction 5). The latter issue accounts for the fact that $R_{4 \mathrm{PP}}>R_{\mathrm{CBP}}$, at least for [4PP] $\geq 30 \mu \mathrm{M}$ (see Figure 3 ).

A further issue is that the value of $R_{1}$ obtained from the fit allows an assessment of the quantum yield of ${ }^{3} \mathrm{CBP} *$ formation under UVA irradiation $\left(\Phi_{{ }^{3} C B P^{*}}\right)$. To determine the photon flux absorbed by CBP one can neglect radiation absorption by 4PP: the absorbance of $0.1 \mathrm{mM}$ 4PP would be as low as 0.05 at $300 \mathrm{~nm}$, and lower to negligible at higher wavelengths (see Figure 1). The maximum absorption of lamp radiation by CBP takes place at $335 \mathrm{~nm}$ (obtained by combining lamp and CBP spectra), where the absorbance of 4PP is below 0.001 . Therefore, the photon flux absorbed by CBP can be calculated as follows:

$$
P_{a}^{C B P}=\int_{\lambda} p^{\circ}(\lambda)\left(1-10^{-\varepsilon_{C B P}(\lambda) b[C B P]}\right) d \lambda
$$


where $p^{\circ}(\lambda)$ is the incident spectral photon flux density of the lamp (Figure 1), $\varepsilon_{\mathrm{CBP}}(\lambda)$ the molar absorption coefficient of CBP, $b=0.4 \mathrm{~cm}$ and $[\mathrm{CBP}]=70 \mu \mathrm{M}$. From equation (9) one gets $P_{a}^{C B P}=(5.5 \pm 0.3) \cdot 10^{-7}$ Einstein $\mathrm{L}^{-1} \mathrm{~s}^{-1}$, thus $\Phi_{{ }^{3} C B P^{*}}=R_{1}\left(P_{a}^{C B P}\right)^{-1}=0.060 \pm 0.012$. Note that higher values of $\Phi_{{ }^{3} C B P^{*}}$ are reported in the literature (Hug et al., 1998). Because $\Phi_{{ }^{3} C B P *}$ was determined from $R_{1}$ in equation (7), a first possibility is that $4 \mathrm{PP}$ degradation by ${ }^{3} \mathrm{CBP} *$ is less effective than here hypothesised due to additional side-reactions. The other possible explanation is an interaction between 4PP and CBP (vide infra), which could alter the yield of ${ }^{3} \mathrm{CBP} *$ formation.

\section{Fluorescence and absorption measurements}

Some additional insight into the behaviour of the CBP + 4PP system was obtained by fluorescence measurements. A first issue is that CBP is not fluorescent, differently from 4PP. However, the presence of $\mathrm{CBP}$ is able to significantly modify the fluorescence emission spectrum of 4PP. Figure 4 reports the fluorescence spectrum of $0.1 \mathrm{mM} 4 \mathrm{PP}$ in the presence of different concentration values of CBP, for excitation at $250 \mathrm{~nm}$ (4a) and at $305 \mathrm{~nm}(4 \mathrm{~b})$. The fluorescence spectrum of 4PP alone excited at $250 \mathrm{~nm}$ shows two intense bands at 320 and $380 \mathrm{~nm}$ (Figure 4a; the band at $500 \mathrm{~nm}$ is the second harmonic of the Rayleigh scattering). The addition of CBP lowers the intensity of the 320-nm band and shifts the 380$\mathrm{nm}$ one to higher wavelengths (the emission maximum of the new band is $\sim 420 \mathrm{~nm}$ ). For excitation at $305 \mathrm{~nm}$, in the case of 4PP alone one observes a broad band at 380-390 nm, which is shifted toward higher wavelengths upon addition of CBP (the new emission maximum is $\sim 430 \mathrm{~nm}$ ). The presence of CBP significantly increases the band intensity as well. The important modification of 4PP fluorescence by CBP suggests that some interaction would take place between the two compounds.

Figure 5 shows the excitation-emission matrix (EEM) fluorescence spectra of $0.1 \mathrm{mM} 4 \mathrm{PP}$ (5a), of $0.1 \mathrm{mM} 4 \mathrm{PP}+70 \mu \mathrm{M} \mathrm{CBP}(5 \mathrm{~b})$, and of $0.1 \mathrm{mM} 4 \mathrm{PP}+70 \mu \mathrm{M}$ CBP after UVA irradiation for $4 \mathrm{~h}(5 \mathrm{c})$ and $16 \mathrm{~h}(5 \mathrm{~d})$. The fluorescence spectrum of $0.1 \mathrm{mM} 4 \mathrm{PP}$ alone shows a series of bands, and particularly those centred at $E x / E m=250 / 375 \mathrm{~nm}$ and 300/375 nm. The shape of the EEM spectrum of 4PP needs some discussion because it is significantly different from that of $e . g$. phenol. In the latter case there are two excitation bands at $\sim 220$ and $\sim 270 \mathrm{~nm}$ and a single emission band centred at $300 \mathrm{~nm}$ (De Laurentiis et al., 2013b), which is consistent with phenol's electronic structure. In fact, radiation absorption by phenol induces electron transitions from $S_{0}$ to either $S_{1}(E x \sim 270 \mathrm{~nm})$ or $S_{2}(E x \sim 220 \mathrm{~nm})$, followed by radiationless relaxation from $S_{2}$ to $S_{1}$ and fluorescence emission from $S_{1}$ alone $(E m \sim 300 \mathrm{~nm})$ (Tchaikovskaya et al., 2002). In the case of 4PP there are two series of bands, which suggests that several excited states (e.g. $\mathrm{S}_{1}$ to $\mathrm{S}_{4}$ ) might be involved in the process. Involvement of multiple excited states in fluorescence is for instance observed in the hydroxylated derivatives 
of anthraquinone-2-sulphonate (AQ2S), which are formed by direct photolysis of AQ2S itself. They have several Ex bands in the range of 200 to $500 \mathrm{~nm}$ and one Em band at $\sim 575 \mathrm{~nm}$ (De Laurentiis et al., 2013b). In the case of 4PP, the presence of two Em bands ( 320 and $\sim 380$ $\mathrm{nm}$ ) instead of only one could be explained by a process of photoinduced intra- or intermolecular proton transfer. In that case, a part of the molecule in the excited state acts as proton donor and another part (or another molecule) as proton acceptor, with formation of two different species with differing emission spectra (Mosquera et al., 1996). Another possible issue is that 4PP is a dimeric species (phenol dimer) that could have two fluorophores, one for each of the phenolic moieties. One fluorophore could be responsible for the emission at $\sim 320$ $\mathrm{nm}$, the other fluorophore for emission at $\sim 380 \mathrm{~nm}$. Alternative explanations such as the formation of 4PP dimers in the ground or excited state can be ruled out, when considering the linear trends with substrate concentration of the absorption and fluorescence spectra of 4PP and the fact that no new bands appear when the concentration of 4PP is modified (data not shown).

In the presence of $0.1 \mathrm{mM} 4 \mathrm{PP}+70 \mu \mathrm{M} \mathrm{CBP}$, one sees a significant shift of 4PP's bands to $\mathrm{Ex} / \mathrm{Em}=250 / 425 \mathrm{~nm}$ and $320 / 425 \mathrm{~nm}$. Interestingly, the second peak is included in the fluorescence region of atmospheric HULIS (Ex/Em = 300-450/400-450 nm; Muller et al., 2008). Considering that compounds such as 4PP and CBP actually occur in the atmosphere (Gomez Alvarez et al., 2012), this finding might give a hint on the fact that HULIS fluorescence might partially derive from supra-molecular interactions between photosensitisers and phenolic compounds.

The UVA irradiation of the 4PP + CBP system modifies the fluorescence intensity of the 250/425 nm and 320/425 nm peaks (Figure 5c,d), but it does not cause a further peak shift or the appearance of new peaks. It should be highlighted that, after $16 \mathrm{~h}$ irradiation, one still has $\sim 20 \%$ of initial $4 \mathrm{PP}$ and $\sim 50 \%$ of initial CBP.

The occurrence of some interaction between 4PP and CBP is further suggested by absorbance measurements. In the absence of interaction, one would expect that the absorption spectrum of a mixture of CBP and 4PP is the sum of the spectra of the separate compounds. Figure 6 shows the absorption spectra of $0.1 \mathrm{mM} 4 \mathrm{PP}$, of $70 \mu \mathrm{M} \mathrm{CBP}$, and of $0.1 \mathrm{mM} 4 \mathrm{PP}+70 \mu \mathrm{M}$ $\mathrm{CBP}$. One can see that the additivity issue might hold for the 4PP absorption band at $230 \mathrm{~nm}$, but certainly not for the CBP band at $270 \mathrm{~nm}$. At such wavelength, both CBP and 4PP significantly absorb radiation and one might expect the absorbance of the mixture to be higher compared to that of CBP alone. Rather surprisingly, the two absorbance values are almost exactly the same. This issue suggests that some modification of the light-absorbing species has taken place in solution, but a dark reaction between 4PP and CBP can be excluded by HPLC data. Therefore, some kind of reversible interaction between the two compounds appears more likely. 
Another interesting issue is the formation of light-absorbing species upon irradiation of 4PP + CBP. Figure 7 reports the absorption spectra of $0.1 \mathrm{mM} 4 \mathrm{PP}+70 \mu \mathrm{M} \mathrm{CBP}$ as a function of UVA irradiation time. Irradiation causes a significant increase of the absorbance in the wavelength interval from 300 to $450 \mathrm{~nm}$, which suggest the formation of new radiationabsorbing compound(s). However, no new EEM fluorescence bands appeared in the irradiated system (Figure 5). Therefore, either the radiation-absorbing material has fluorescence bands in the region $\mathrm{Ex} / \mathrm{Em}=250 / 425 \mathrm{~nm}$ and $320 / 425 \mathrm{~nm}$, thereby overlapping with $4 \mathrm{PP}+\mathrm{CBP}$, or it is not fluorescent. Interestingly, formation of light-absorbing but non-fluorescent material has been observed upon sensitised degradation of the phenolic molecule tyrosine (Berto et al., 2013), which is known to undergo oligomerisation and polymerisation processes under oxidative conditions (Fontana et al., 2001).

\section{Degradation of 4PP coated on silica particles}

The degradation of 4PP coated on silica particles, induced by heterogeneous reactions with ozone in presence of CBP as a photosensitiser was largely studied by Gligorovski and coworkers (Nieto-Gligorovski et al. 2008, Nieto-Gligorovski et al., 2010, Net et al., 2009, 2010). It has been shown that light-induced heterogeneous reactions of ozone with 4PP, coated on silica with CBP as photosensitiser lead to the formation of compounds with properties and composition similar to humic like substances (HULIS) found in atmospheric aerosols (Nieto-Gligorovski et al., 2008, 2010). The formation of such substances was confirmed by Net et al. (2009), where a number of oligomers were identified following either ozone processing or simultaneous ozone processing and light irradiation of 4PP/CBP coated particles. It was suggested that the formation of oligomers is initiated by $\mathrm{C}-\mathrm{O}$ and $\mathrm{C}-\mathrm{C}$ coupling dimers (Net et al., 2009) involving the phenoxy radicals formed through reaction (4) (see section "Experiments under continuous irradiation").

The interaction between $\mathrm{CBP}$ and 4PP in aqueous solution, in the absence of ozone, modifies the fluorescence spectrum of 4PP and gives rise to new bands that overlap with the fluorescence bands of HULIS substances (see above, "Fluorescence and absorption measurements", and Figure 5). In addition, Net et al. (2010) have demonstrated that CBP enhances the degradation of 4PP on coated particles under irradiation in the presence of an atmospheric oxidant such as ozone.

In this study, for the first time to our best knowledge, we evaluated the transformation of 4PP on the surface of silica particles, photosensitised by CBP in the absence of ozone. As shown above (see section "Steady irradiation experiments") and in agreement with the literature (Canonica et al., 2000), CBP forms excited triplet states in high yields upon UVA irradiation in aqueous solution. However, the triplet yields of CBP on particles can differ from those in the aqueous phase, because the surface can modify the light-absorption properties. The excited triplet state of CBP is known to act as a one-electron oxidant (George et al., 2005, 
Jammoul et al., 2008), which enables reactivity with electron-donor substituted phenols such as 4PP. The degradation of 4PP by irradiated CBP (likely involving ${ }^{3} \mathrm{CBP}^{*}$ ) was assessed at different relative humidities $(\mathrm{RH})$ as shown in Figure 8. Experimental data points were fitted using first-order exponential functions. The error bars represent the $1 \sigma$ uncertainty levels based on the average of two replicate experiments.

The figure shows that 4PP degradation decreases with increasing relative humidity. The firstorder decay constants $\left(\mathrm{k}_{1 \mathrm{st}}\right)$ of $4 \mathrm{PP}$ were $(0.15 \pm 0.019) \mathrm{s}^{-1},(0.11 \pm 0.02) \mathrm{s}^{-1}$ and $(0.06 \pm 0.03)$ $\mathrm{s}^{-1}$ at RH of $0 \%, 70 \%$ and $95 \%$, respectively. At $95 \% \mathrm{RH}$ the first-order decay constant of 4PP was two-three times lower compared to $0 \% \mathrm{RH}$. The distinctive feature of 4PP degradation sensitised by ${ }^{3} \mathrm{CBP} *$ in water is that the primary event is most likely an electron transfer to the triplet state of the photosensitiser. In this case, prototropic interactions between reactants that play a certain role in organic media are insignificant in water. A decrease in the reaction energy most likely occurs due to the solvation of both compounds (4PP and CBP) by water molecules. The prototropic interactions with water allow the "classical" outer-sphere electron transfer to occur, which requires no specific orientation of the reactants in the encounter complex (Sultimova et al., 2005).

Depending on their origin and conditioning, aerosol particles containing organic compounds can have complex and highly porous microstructures, which are influenced by electric charge effects and interaction with water vapour. In our previous study it has been shown that heterogeneous reactions of ozone with 4PP in the presence of CBP as photosensitiser led to the formation of oligomers (Nieto-Gligorovski et al., 2010) that are hydrophobic (NietoGligorovski et al., 2008). Oligomers and other surfactants tend to be enriched at the particle surface (Poeschl, 2005). They can form an envelope that can inhibit the access of water vapour to the particle core, thereby causing kinetic limitations of hygroscopic growth, phase transitions, and $\mathrm{CCN}$ activation.

These and other effects of the interaction between organic and inorganic aerosol components $\left(\mathrm{SiO}_{2}\right.$ in this case) ought to be elucidated further. They should be considered for a reliable analysis of measurement data from laboratory experiments and field measurements, including the consistent modelling of atmospheric aerosol processes.

\section{UV-VIS spectra of $4 P P$ and CBP}

The $n \rightarrow \pi^{*}$ excited state of a carbonyl group is less dipolar but more polarisable than the ground state. It has been demonstrated that the dipole moment of the lowest singlet $n \rightarrow \pi^{*}$ excited state of benzophenone $(\mu=1.5 \mathrm{D})$ is only half as large as the dipole moment of the ground state $(\mu=3.0 \mathrm{D})$. This decrease of the dipole moment leads to a blue shift of the $\mathrm{n} \rightarrow \pi^{*}$ absorption band with increasing solvent polarity. For example, a small blue shift of $\Delta \lambda=-8$ $\mathrm{nm}$ was observed for the $\mathrm{n} \rightarrow \pi^{*}$ transition of benzophenone when going from apolar $\mathrm{n}$-hexane to dipolar aprotic acetonitrile as solvent (Reichardt, 2003). 
Figure 9 reports the UV-VIS spectra of CBP, which is a benzophenone derivative, in dichloromethane (DCM) as solvent. According to Reichardt's solvent polarity scale, DCM is a dipolar non hydrogen-bonding donor solvent (Reichardt, 2003). It was chosen here to avoid the strong solute/solvent interactions that occur in hydroxylic solvents such as water (Scott, 1961), thereby preventing the stabilisation of the more polar states in the electronic transition due to solvation effects. It is interesting to observe that CBP in DCM has an absorption band that is extended well above $400 \mathrm{~nm}$, into the visible range. By comparison, CBP in water has negligible absorption above $350 \mathrm{~nm}$ (see for instance Figure 1 or Figure 6). If interaction with water can shift CBP absorption from visible to UV wavelengths, thereby decreasing the potential of CBP to act as photosensitiser under simulated sunlight, that might explain the inhibition by water vapour of the CBP-sensitised transformation of 4PP. This would happen because the $n \rightarrow \pi^{*}$ excited state of the carbonyl group is supposed to be responsible for the degradation of 4PP (Reinchardt, 2003). However, it must be noted that absorption spectra can be quite different on the surface of the aerosol particles in comparison to solvents.

\section{Conclusions}

Chemical reactions proceed at the surface and in the bulk of solid and liquid aerosol particles and can influence atmospheric gas-phase chemistry, as well as the properties of atmospheric particles and their effects on climate and human health (Poeschl, 2005). In this study, two complementary experimental techniques were used to assess the photosensitised degradation of $4 \mathrm{PP}$ by ${ }^{3} \mathrm{CBP} *$, in aqueous solution and on the surface of silica particles.

The present findings strongly suggest that photosensitised degradation of organic compounds adsorbed on the surface of aerosol particles may be an effective degradation pathway in comparison to the removal of organics induced by atmospheric oxidants such as ${ }^{\circ} \mathrm{OH}, \mathrm{O}_{3}$, and $\cdot \mathrm{NO}_{3}$.

Obviously the photosensitised chemistry taking place on the particles can alter the atmospheric fate of the particles themselves by modifying their optical properties through differences in hygroscopicity or chemical composition or by affecting their ability to act as cloud condensation nuclei. Moreover, the photodegradation of $4 \mathrm{PP}$ induced by ${ }^{3} \mathrm{CBP}^{*}$ in aqueous solution contributes to the formation of high molecular weight compounds, such as HULIS, that absorb light at wavelengths $>290 \mathrm{~nm}$, leading to consequences on climate warming (direct effect on climate).

Keeping in mind that atmospheric aerosols contain an important fraction of photosensitisers, and knowing the potential of photosensitisers to induce phototransformation and enhance the loss of organic molecules (Anastasio et al., 1997; George et al., 2005; Vione et al., 2006, Net 
et al., 2009, Net et al., 2010), further studies over this topic are strongly recommended in the future.

\section{Acknowledgements}

The PhD grant of EDL was financially supported by Progetto Lagrange - Fondazione CRT (Torino, Italy). DV acknowledges financial support by MIUR - PRIN 2009 (project 20092C7KRC-ARCTICA), PNRA - Progetto Antartide and University of Torino - EU Accelerating Grants, project TO_Cal12_2012_0047 (DOMNAMICS). DV and MB thank EGIDE and Università Italo-Francese (Progetto Galileo) for financial support.

\section{References}

Alegría, A.E., Ferrer, A., Santiago, G., Sepúlveda E., Flores, W., 1999. Photochemistryof water-soluble quinones. Production of hydroxyl radical, singlet oxygen and the superoxide ion. Journal of Photochemistry and Photobiology A: Chemistry 127, 57-65.

Anastasio, C., Faust, B. C., and Janakiram Rao, C., 1997. Aromatic carbonyl compounds as aqueous-phase photochemical sources of hydrogen peroxide in acidic sulfate aerosols, fogs, and clouds, I. Non-phenolic methoxybenzaldehydes and methoxyacetophenones with reductants (phenols). Environmental Science and Technology 31, 218- 232.

Barbas, J.T., Sigman, M.E., Dabestani, R., 1996. Photochemical oxidation of phenanthrene sorbed on silica gel. Environmental Science and Technology 30, 1776-1780.

Bari, M.A., Baumbach, G., Kuch, B., Scheffknecht, G., 2009. Wood smoke as a source of particle-phase organic compounds in resedential areas. Atmospheric Environment 43, $4722-4732$.

Bedini, A., De Laurentiis, E., Sur, B., Maurino, V., Minero, C., Brigante, M., Mailhot, G., Vione, D., 2012. Phototransformation of anthraquinone-2-sulphonate in aqueous solution. Photochemical and Photobiological Sciences 11, 1445-1453.

Berto, S., Isaia, M., Sur, B., De Laurentiis, E., Barsotti, F., Buscaino, R., Maurino, V., Minero, C., Vione, D., 2013. UV-vis spectral modifications of water samples under irradiation: Lake vs. subterranean water. Journal of Photochemistry and Photobiology A: Chemistry 251, 85-93.

Canonica, S., Hellrung, B., and Wirz, J., 2000. Oxidation of phenols by triplet aromatic ketones in aqueous solution, Journal of Physical Chemistry A, 104, 1226-1232.

Canonica, S., Freiburghaus, M., 2011. Electron-rich phenols for probing the photochemical reactivity of freshwaters. Environmental Science and Technology 35, 690-695. 
Clark, K.P., Stonehill, H.I., 1972. Photochemistry and radiation chemistry of anthraquinone2-sodium-sulphonate in aqueous solution. Part 1.-Photochemical kinetics in aerobic solution. Journal of the Chemical Society - Faraday Transactions I 68, 577-590.

De Laurentiis, E., Sur, B., Pazzi, M., Maurino, V., Minero, C., Mailhot, G., Brigante, M., Vione, D., 2013a. Phenol transformation and dimerisation, photosensitised by the triplet state of 1-nitronaphthalene: A possible pathway to humic-like substances (HULIS) in atmospheric waters. Atmospheric Environment 70, 318-327.

De Laurentiis, E., Maurino, V., Minero, C., Vione, D., Mailhot, G., Brigante, M., 2013b. Could triplet-sensitised transformation of phenolic compounds represent a source of fulvic-like substances in natural waters? Chemosphere 90, 881-884.

Dixon, W.T., Murphy, D., 1976. Determination of the acidity constants of some phenol radical cations by means of electron spin resonance. Journal of the Chemical Society Faraday Transactions II, 1221-1230.

Feilberg, A., Nielsen ,T., 2000. Effect of aerosol chemical composition on the photodegradation of nitro-polycyclic aromatic hydrocarbons. Environmental Science and Technology 34, 789-797.

Fontana, M., Mosca, L., Rosei, M.A., 2001. Interaction of enkephalins with oxyradical. Biochemical Pharmacology 61, 1253-1257.

Gadosy, T. A., Shukla, D., Johnston, L. J., 1999. Generation, characterization and deprotonation of phenol radical cations. Journal of Physical Chemistry A 103, 8834-8839.

George, C., Strekowski, R. S., Kleffmann, J., Stemmler, K., and Ammann, M., 2005. Photoenhanced uptake of gaseous $\mathrm{NO}_{2}$ on solidorganic compounds: a photochemical source of HONO? Faraday Discussussion, 130, 195-210.

Gomez Alvarez E., Wortham H., Strekowski R., Zetzsch C., Gligorovski S., 2012. Atmospheric photo-sensitized heterogeneous and multiphase reactions: From outdoors to indoors. Environmental Science and Technology 46, 1955-1963.

Hawthorne, S.B, Miller, D.J., Barkley, R.M., Krieger, M.S., 1988. Identification of Methoxylated Phenols as Candidate Traces for Atmospheric Wood Smoke Pollution, Environmental Science and Technology, 22, 1191-1196.

Hawthorne, S.B, Krieger, M.S., Miller, D.J., Mathlason, M.B., 1989. Collection and Quantitation of Methoxylated Phenol Tracers for Atmospheric Pollution from Residential Wood Stoves, Environmental Science and Technology , 23, 470-475.

Hawthorne, S.B, Miller, D.J., Langenfeld, J.J. Krieger, M.S., 1992. PM-10 high volume collection and quantitation of semi- and nonvolatile phenols, methoxylated phenols, alkanes, and polycyclic aromatic hydrocarbons from winter urban air and their relationship to wood smoke emissions, Environmental Science and Technology, 26, 22512262. 
Hug, G. L., Bobrowskil, K., Kozubek, H., Marciniak, B., 1998. Photooxidation of methionine derivatives by the 4-carboxybenzophenone triplet state in aqueous solution. Intracomplex proton transfer involving the amino group. Photochemistry and Photobiology 68, 785-796.

Jammoul, A., Gligorovski, S., George, C., and D'Anna, B. 2008. Photosensitized Heterogeneous Chemistry of Ozone on Organic Films, Journal of Physical Chemistry A, $112,1268-1276$.

Jang, M. and McDow, S. R., 1995. Benz[a]anthracene photodegradation in the presence of known organic constituents of atmospheric aerosols, Environmental Science and Technology, 29, 2654-2660.

Jang, M. and McDow, S. R., 1997. Product of Benz[a]anthracene photodegradation in the presence of known organic constituents of atmospheric aerosols, Environmental Science and Technology, 31, 1046-1053.

Kuhn, H.J., Braslavsky, S.E., Schmidt, R., 2004. Chemical actinometry. Pure and Applied Chemistry 76, 2105-2146.

Lesh, S.A, Mead, R.C., 1985. Sources screening for phenol. Prepared by Radian Corporation for U.S. Environmental Protection Agency, Research Triangle Park, N.C, Contract No. 68-02-3889.

Ma, J.H., Shao, H., Yao, S.D., Lin, N.Y., 2000. Photoinduced electron transfer reaction between poly-guanylic acid (5') with anthraquinone-2-sulfonate. Chinese Chemistry Letters 11, 527-530.

Maurino, V., Borghesi, D., Vione, D., Minero, C., 2008. Transformation of phenolic compounds upon UVA irradiation of anthraquinone-2-sulphonate. Photochemical \& Photobiological Sciences 7, 321-327.

Mosquera, M., Penedo, J. C., Ríos Rodríguez, M. C., Rodríguez-Prieto, F., 1996. Photoinduced inter- and intramolecular proton transfer in aqueous and ethanolic solutions of 2-(2ф-hydroxyphenyl)benzimidazole: Evidence for tautomeric and conformational equilibria in the ground state. Journal of Physical Chemistry 100, 5398-5407.

Muller, C.L., Baker, A., Hutchinson, R., Fairchild, I. J., Kidd, C., 2008. Analysis of rainwater dissolved organic carbon compounds using fluorescence spectrophotometry. Atmospheric Environment 42, 8036-8045.

Net S., Nieto-Gligorovski L., Gligorovski S., Temime-Roussel B., Barbati S., Lazarou Y.G., Wortham H., 2009. Heterogeneous light induced ozone processing on the organic coatings in the atmosphere. Atmospheric Environment, 43(9), 1683-1692.

Net S., Gligorovski S., Pietri S., Wortham H., 2010. Photoenhanced degradation of veratraldehyde upon the heterogeneous ozone reactions. Physical Chemistry Chemical Physics 12, 7603-7611. 
Net S., Nieto-Gligorovski L., Gligorovski S., Wortham H., 2010. Heterogeneous ozonation kinetics of 4-phenoxyphenol in the presence of photosensitizer. Atmospheric Chemistry and Physics 10, 1545-1554.

Nieto-Gligorovski L., Net S., Gligorovski S., Zetzsch C., Jammoul A., D’Anna B., George C., 2008. Interactions of ozone with organic surface films in the presence of simulated sunlight: Impact on wettability of aerosols. Physical Chemistry Chemical Physics 10, 2964-2971.

Nieto-Gligorovski L.I., Net S., Gligorovski S., Wortham H., Grothe C., Zetzsch C., 2010. Spectroscopic study of organic coatings on fine particles, exposed to ozone and simulated sunlight. Atmospheric Environment, 44 (40), 5451-5459.

Park, H.W., Kim, J.K., Hong, U.G., Lee, Y.J., Song, J.H., Song, I.K. 2013 Catalytic decomposition of 4-phenoxyphenol over Pd/XCs2.5H0.5PW12O40/ACA (activated carbon aerogel)-SO3H (X=10-30 wt\%) catalysts, Applied Catalysis A: General 453, 287294.

Perzon, M., 2010. Emissions of organic compounds from the combustion of oats e a comparison with softwood pellets. Biomass and Bioenergy. 34, 828-837.

Pöschl U., 2005. Atmospheric aerosols: composition, transformation, climate and health effects. Angewandte Chemie International Edition, 44, 7520 - 7540.

Reinchardt, C. 2003. Solvents and solvent effects in organic chemistry. $3^{\text {rd }}$ ed., Wiley-VCH, Weinheim.

Simoneit, B.R.T., 2002. Biomass burning e a review of organic tracers for smoke from incomplete combustion. Applied Geochemistry 17, 129-162.

Sul'timova, N. B., Levin, P. P., Chaikovskaya, O. N. (2005). Kinetics of radical formation and decay in photooxidation of 4-halophenols sensitized by 4-carboxybenzophenone in aqueous solutions. Russian Chemical Bulletin, International Edition, 54, 1439-1444.

Tchaikovskaya, O., Sokolova, I., Bazyl, O., Swetlichnyi, V., Kopylova, T., Mayer, G., Sultimova, N., 2002. The fluorescence analysis of laser photolysis of phenols in water. International Journal of Photoenergy 4, 79-83.

Vione, D., Maurino, V., Minero, C., Pelizzetti, E., Harrison, M.A.J., Olariu, R.-I., Arsene, C., 2006. Photochemical reactions in the tropospheric aqueous phase and on particulate matter. Chemical Society Review. 35, 441-453.

Yee, L. D., Kautzman, K. E., Loza, C. L., Schilling, K. A., Coggon, M. M., Chhabra, P. S., Chan, M. N., Chan, A. W. H., Hersey, S. P., Crounse, J. D., Wennberg, P. O., Flagan, R. C., Seinfeld, J. H., 2013. Secondary organic aerosol formation from biomass burning intermediates: phenol and methoxyphenols. Atmospheric Chemistry and Physics Discussions. 13, 3485-3532. 


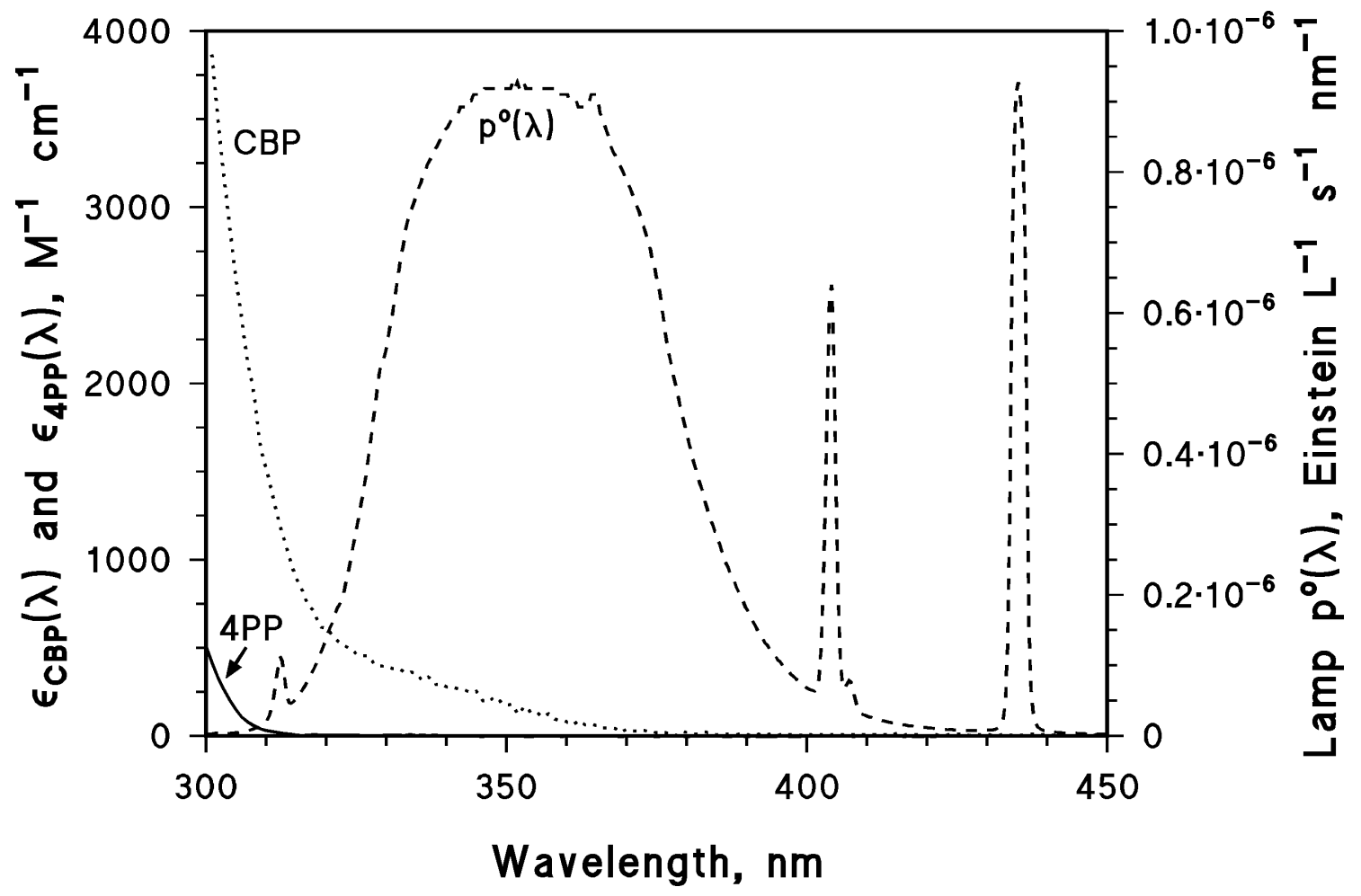

Figure 1. Emission spectrum of the TLO9N UVA lamp used for irradiation experiments in solution. Absorption spectra of CBP and 4PP in aqueous solution. 


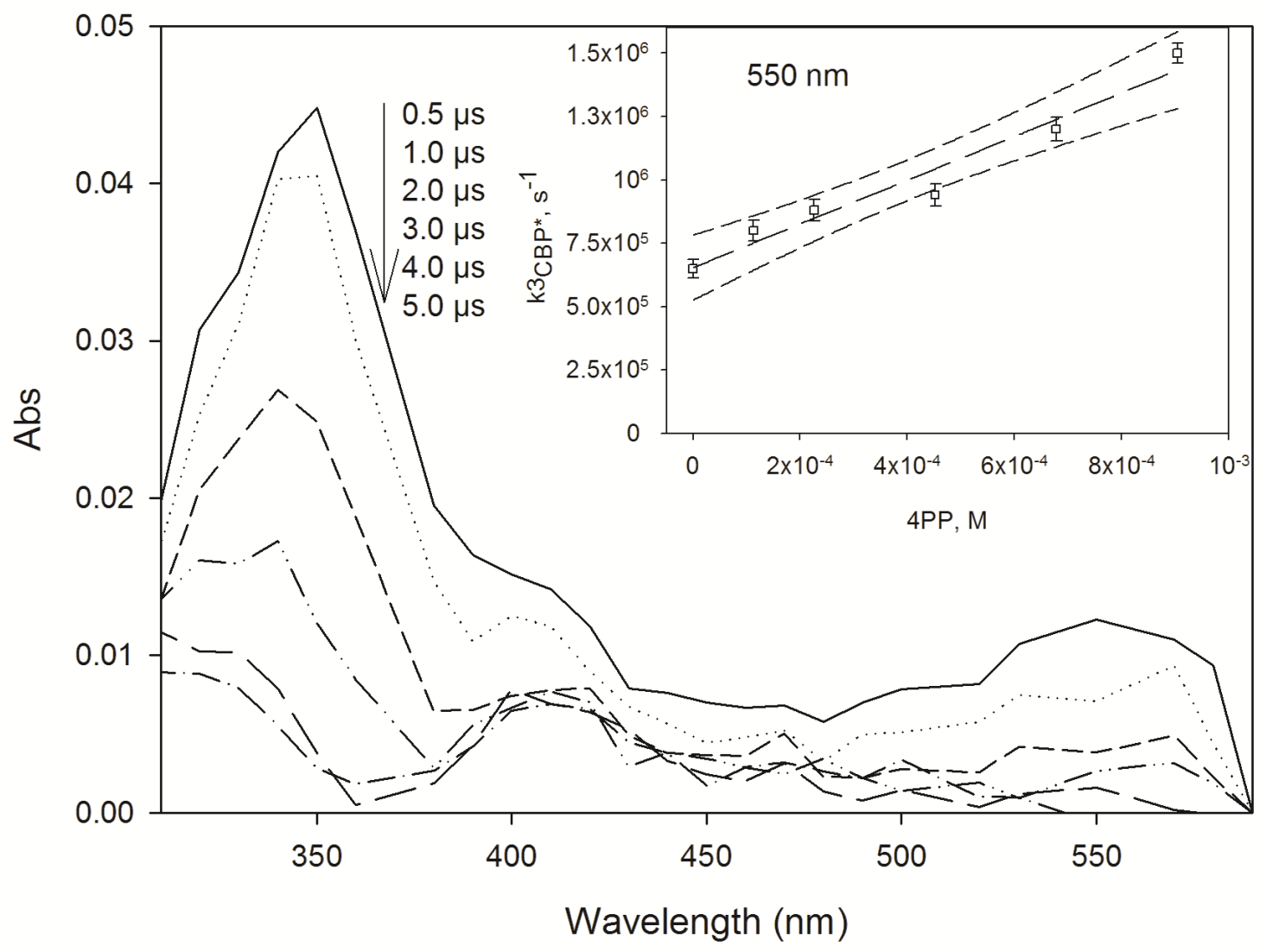

Figure 2. Transient absorption spectra produced upon LFP $(355 \mathrm{~nm}, 45 \mathrm{~mJ})$ of CBP in the presence of $4 \mathrm{PP}\left(5.5 \times 10^{-4} \mathrm{M}\right)$ at ambient temperature. Insert: trend of the firstorder decay constant of ${ }^{3} \mathrm{CBP}^{*}, k_{C B P^{*}}$, as a function of the concentration of 4PP. The error bars are derived at the $1 \sigma$ level upon calculation of $k_{C B P^{*}}$ from flash photolysis traces, the dashed line is the data fit with the Stern-Volmer equation, the dotted curves are the $95 \%$ confidence limits of the fit. 

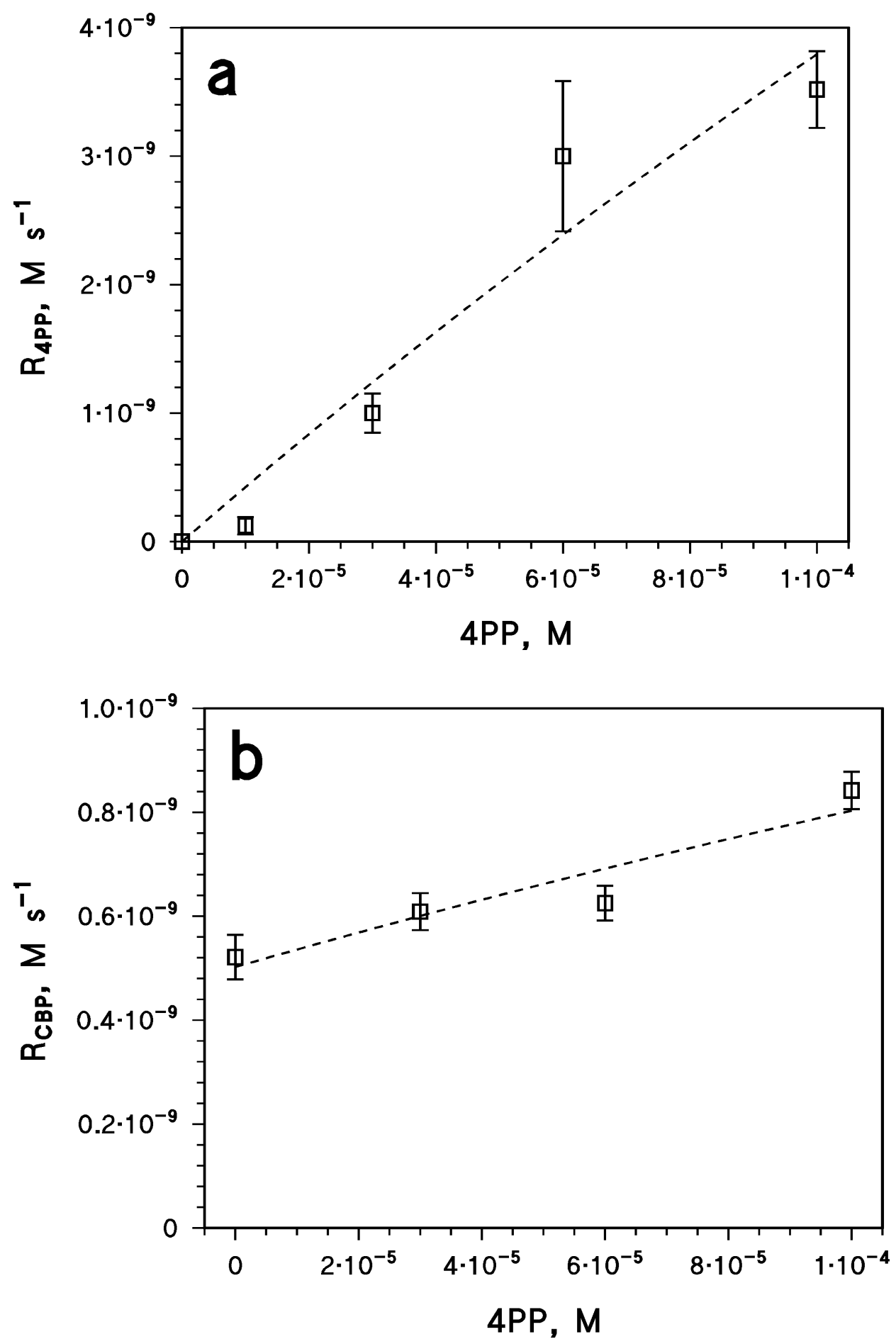

Figure 3. (a) Trend of $4 \mathrm{PP}$ initial transformation rate, $R_{4 \mathrm{PP}}$, as a function of $4 \mathrm{PP}$ concentration, after subtraction of the rate of direct photolysis. The dashed curve is the fit of the experimental data with equation (7). Initial conditions: $70 \mu \mathrm{M}$ CBP, pH 7, UVA irradiation.

(b) Trend of $\mathrm{CBP}$ initial transformation rate, $R_{\mathrm{CBP}}$, as a function of $4 \mathrm{PP}$ concentration. The dashed curve is the fit of the experimental data with equation (8). Initial conditions: $70 \mu \mathrm{M} \mathrm{CBP}, \mathrm{pH} 7$, UVA irradiation. 

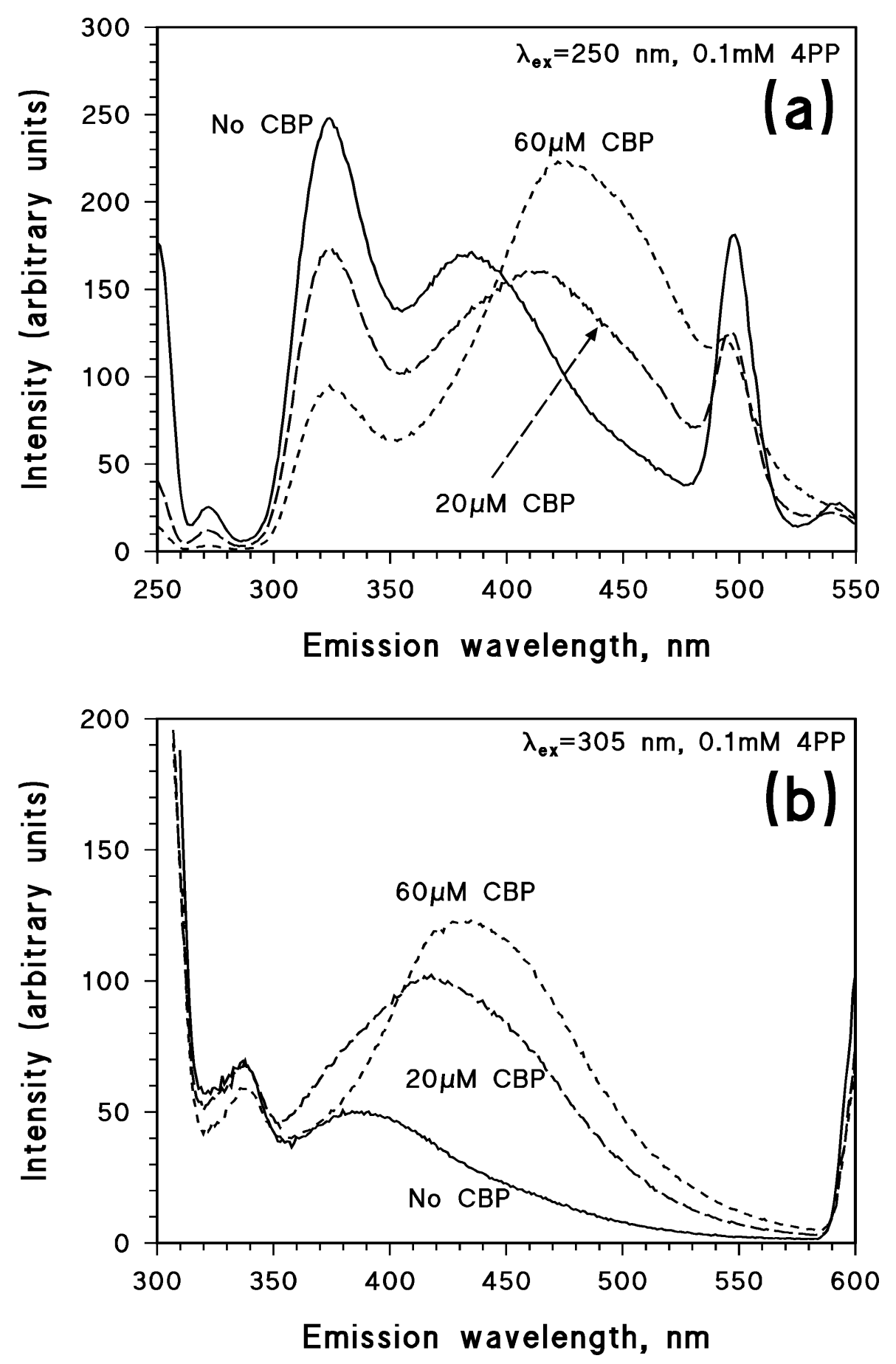

Figure 4. (a) Fluorescence emission spectrum of $0.1 \mathrm{mM} 4 \mathrm{PP}$ upon excitation at $250 \mathrm{~nm}$, in the presence of different concentration values of CBP.

(b) Fluorescence emission spectrum of $0.1 \mathrm{mM} 4 \mathrm{PP}$ upon excitation at $305 \mathrm{~nm}$, in the presence of different concentration values of CBP. 


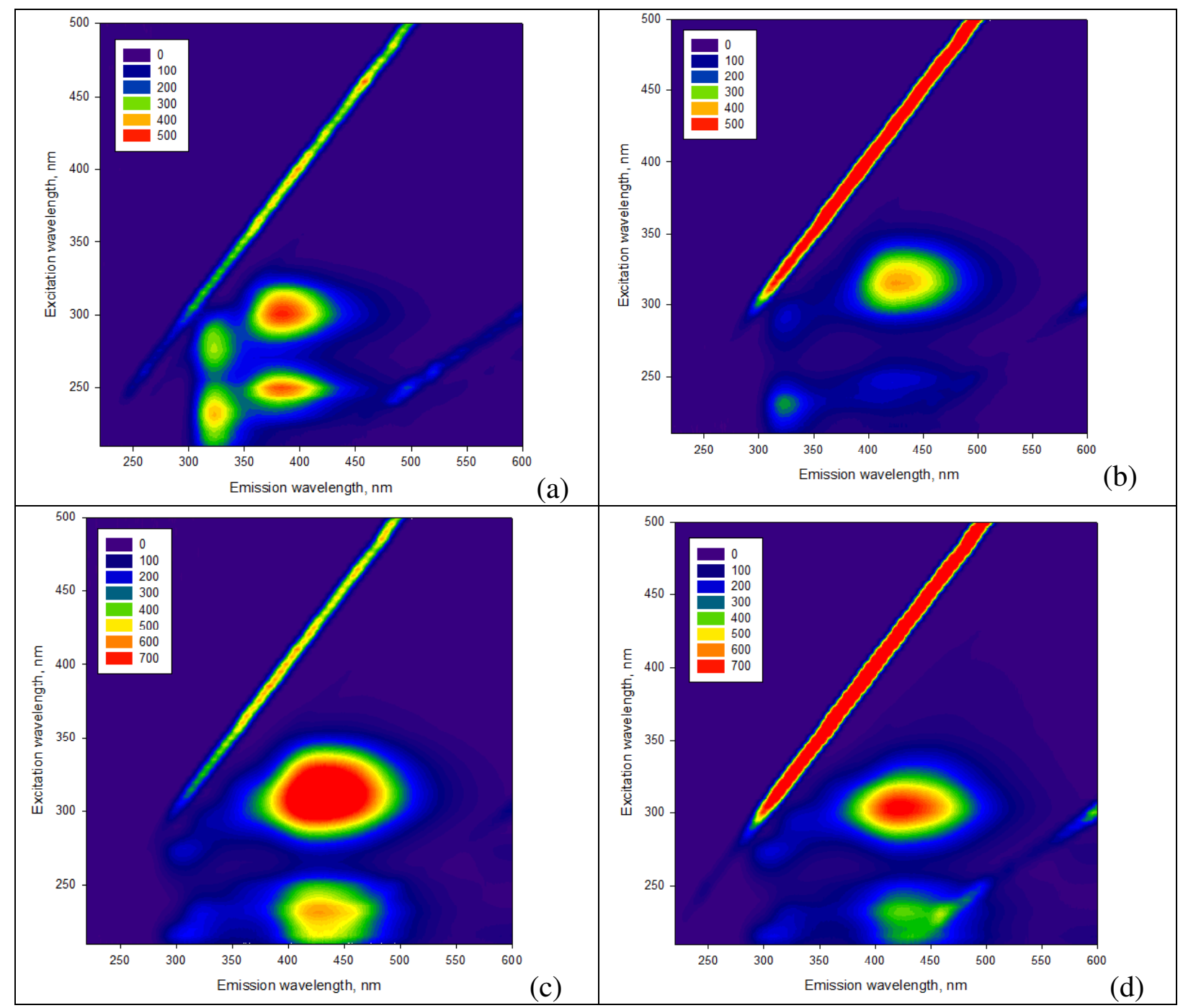

Figure 5. Excitation-emission matrix (EEM) fluoresce spectra of: (a) $0.1 \mathrm{mM}$ 4PP; (b) 0.1 $\mathrm{mM} 4 \mathrm{PP}+70 \mu \mathrm{M} \mathrm{CBP}$; (c) $0.1 \mathrm{mM} 4 \mathrm{PP}+70 \mu \mathrm{M} \mathrm{CBP}$ after $4 \mathrm{~h}$ of UVA irradiation; (d) $0.1 \mathrm{mM} 4 \mathrm{PP}+70 \mu \mathrm{M} \mathrm{CBP}$ after $16 \mathrm{~h}$ of UVA irradiation. 


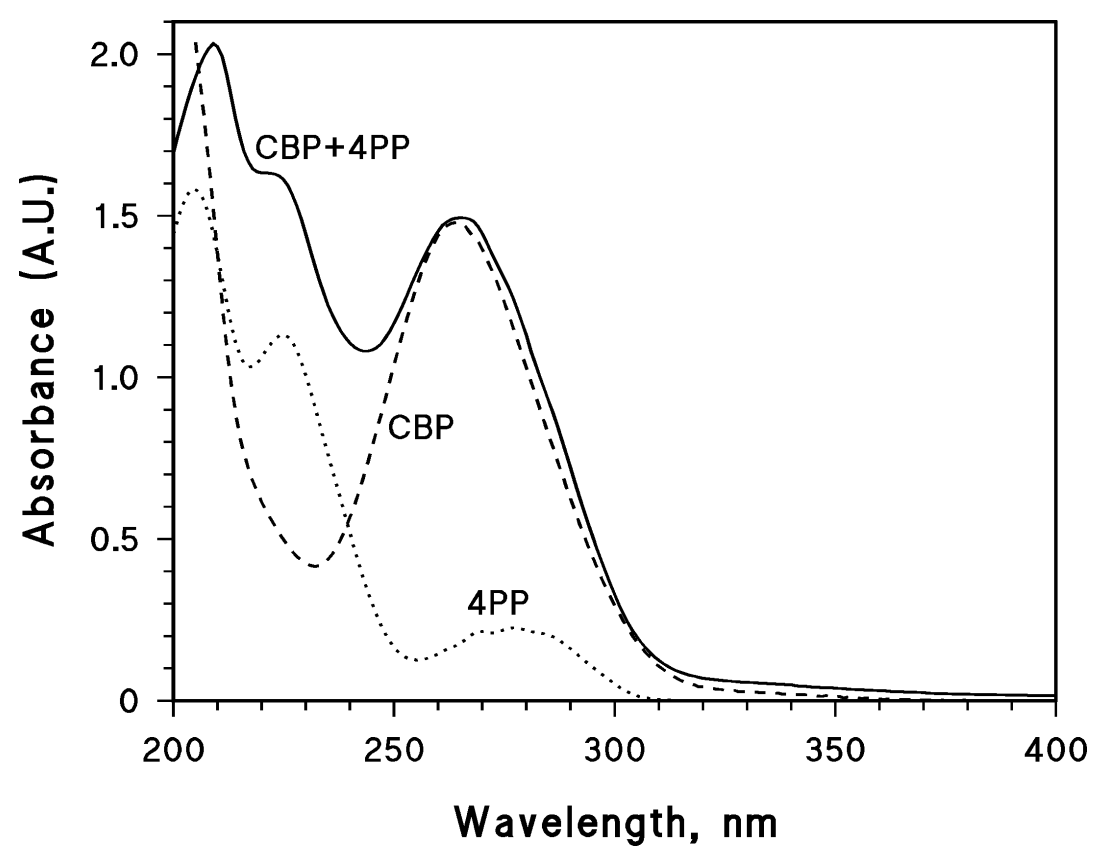

Figure 6. Absorption spectra ( $1 \mathrm{~cm}$ optical path length, $\mathrm{pH} 7)$ of $0.1 \mathrm{mM} 4 \mathrm{PP}$, of $70 \mu \mathrm{M} \mathrm{CBP}$, and of $0.1 \mathrm{mM} 4 \mathrm{PP}+70 \mu \mathrm{MCBP}$.

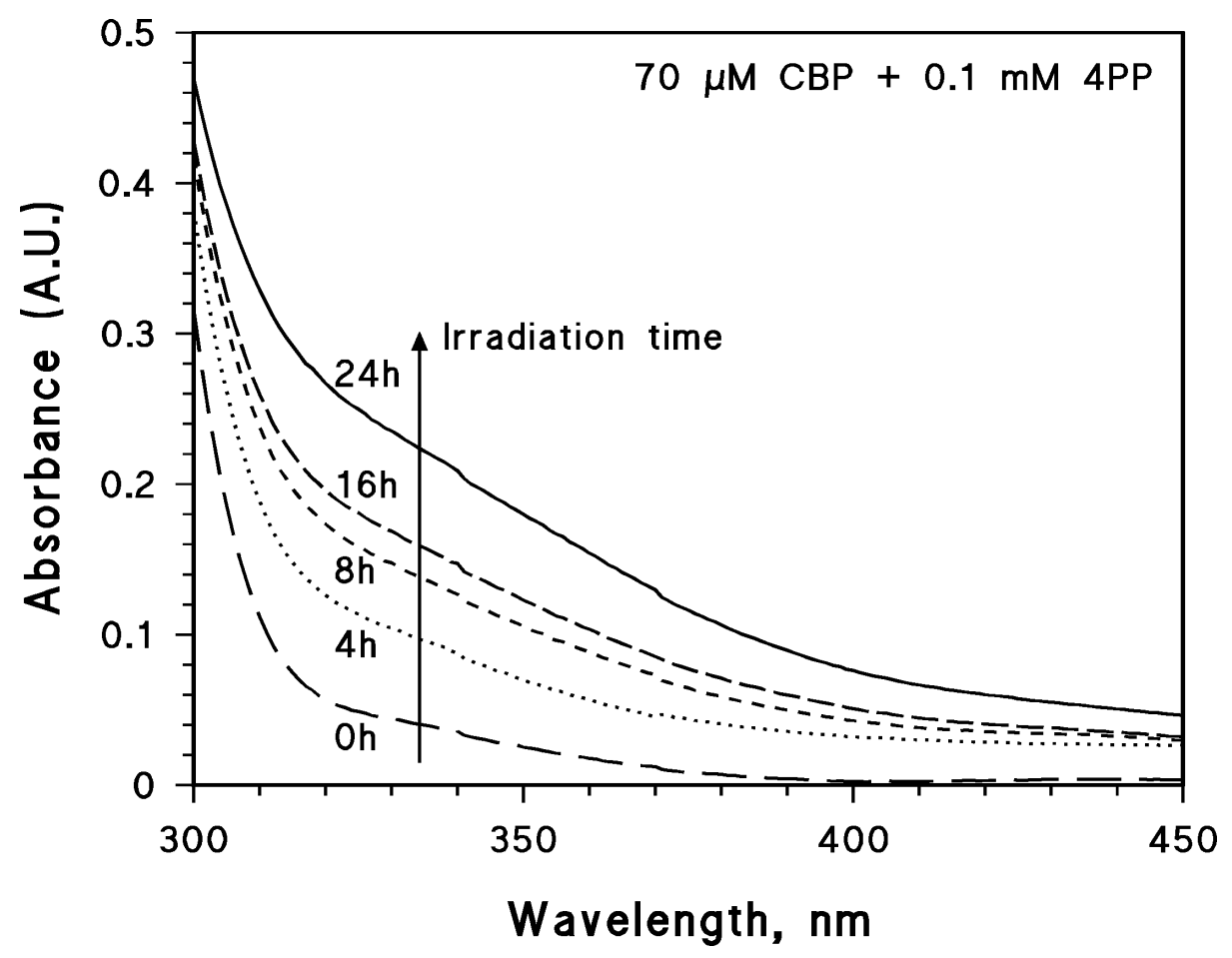

Figure 7. Absorption spectra of $0.1 \mathrm{mM} 4 \mathrm{PP}+70 \mu \mathrm{MCBP}$ as a function of irradiation time (UVA irradiation, $\mathrm{pH} 7$ ). 


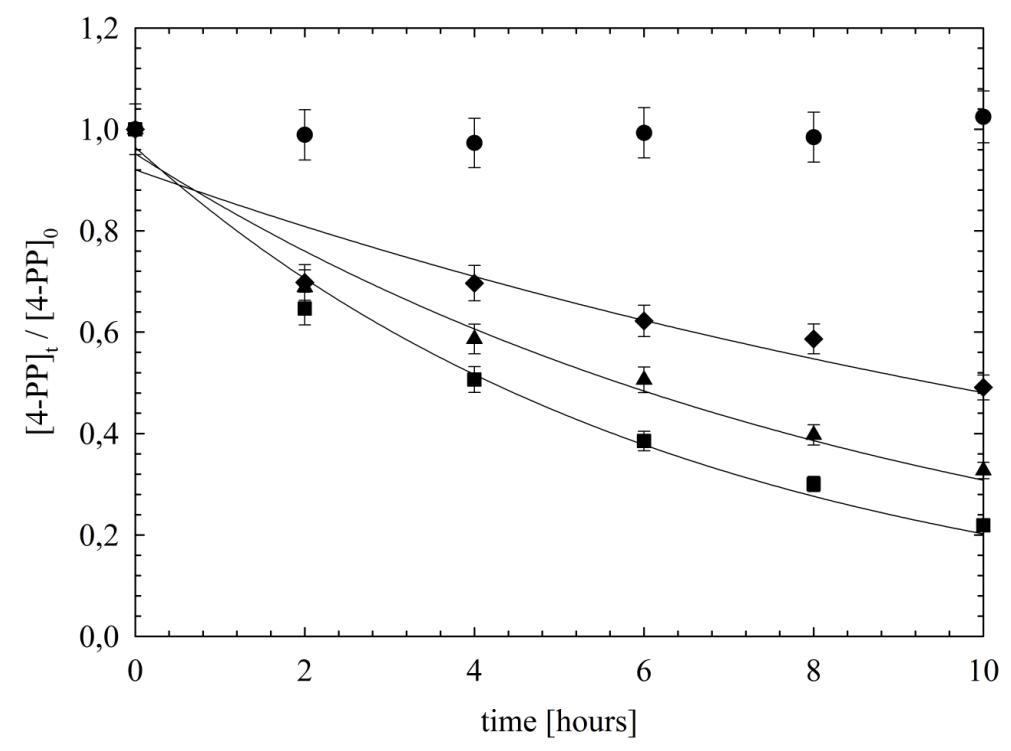

Figure 8. First-order decays of $4 \mathrm{PP}$ coated on silica particles, induced by ${ }^{3} \mathrm{CBP}^{*}$, as a function of relative humidity. •) Blank experiment (no exposure of the coated particles); $\boldsymbol{\square}) \mathrm{RH}=0 \%$; $\mathbf{\Delta}) \mathrm{RH}=70 \%$; ) $\mathrm{RH}=95 \%$. The error bars represent $1 \sigma$ uncertainty levels, based on the average of two repeated experiments.

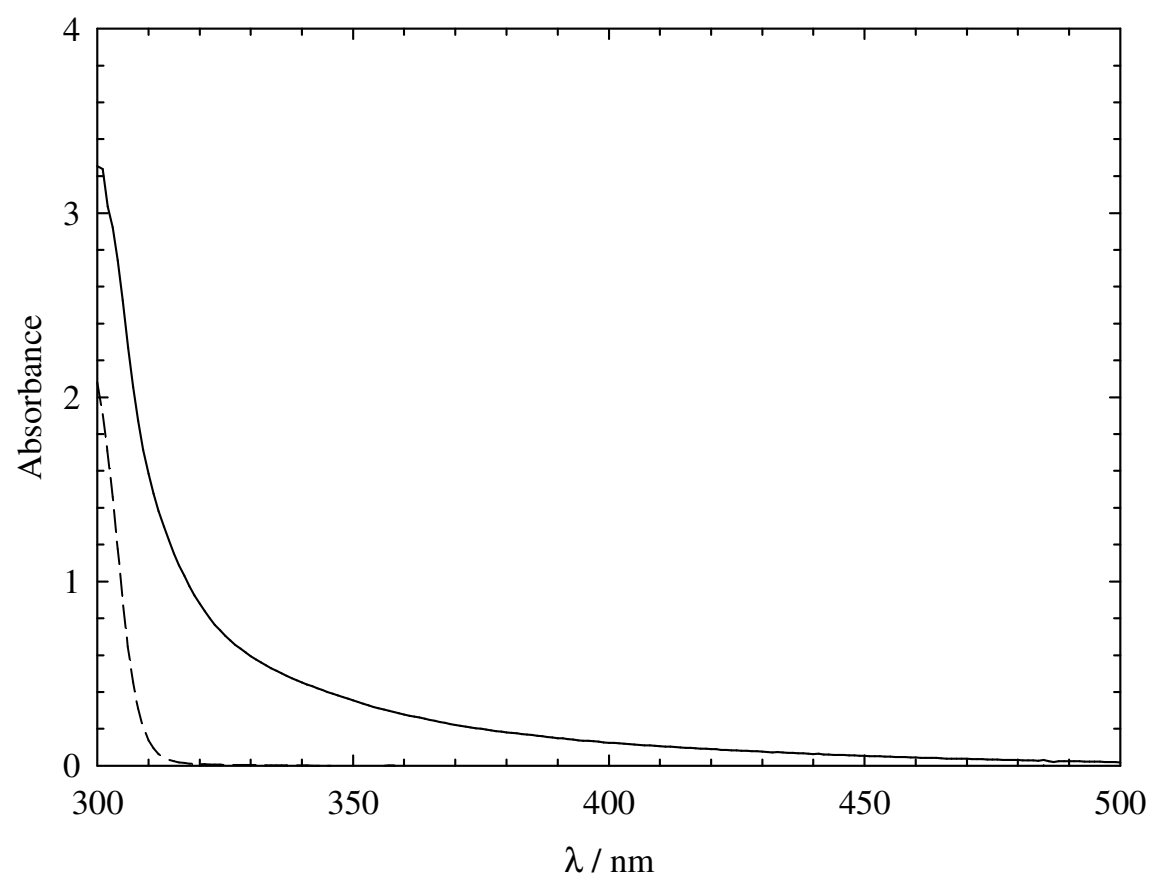

Figure 9. Absorption spectra of 4PP (dashed) and CBP (solid) in dichloromethane. The concentration of 4-PP and CBP is $5 \cdot 10^{-4} \mathrm{~mol} \mathrm{~L}^{-1}$, the cell path length is $1 \mathrm{~cm}$. 